\title{
EDITORIAL
}

\section{Advances and perspectives in child and adolescent psychiatry}

\author{
Christian Kieling, ${ }^{1}$ Guilherme V. Polanczyk ${ }^{2}$ \\ ${ }^{1}$ Universidade Federal do Rio Grande do Sul (UFRGS), Porto Alegre, RS, Brazil. ${ }^{2}$ Universidade de São Paulo (USP), São Paulo, SP, Brazil.
}

Child and adolescent psychiatry is a relatively new but extremely promising medical discipline. Significant advances have been accomplished in the understanding and treatment of mental disorders in childhood over the last decades, and many new discoveries are expected in the forthcoming years. Unfortunately, progress has not occurred homogeneously across regions in the world and within countries. In Brazil, a small number of academic centers have led the work, and there is an urgent need of more investigators. In addition, a huge proportion of children and adolescents suffering from mental, emotional, and behavioral disorders across the country remain undiagnosed and untreated. This special issue of Revista Brasileira de Psiquiatria presents six articles focusing on relevant mental disorders that affect children and adolescents. Articles are clinically oriented, but also address advances in the investigation of these disorders, providing readers with a broad perspective on the topic.

Salum et al. ${ }^{1}$ review the neurobiological aspects of anxiety disorders early in life, linking new research to evidence-based strategies to diagnose and treat pediatric anxiety disorders. Unipolar depression and bipolar disorder are covered in the article by Rocha et al. ${ }^{2}$ Mood disorders are the leading cause of disability among young individuals; moreover, due to their association with suicide, mood disorders are also linked to significant mortality in this age group. Despite significant advances over the past few years, the developmental presentation of mood episodes still poses challenges to clinicians. Irritability - probably the single most debated symptom in the recent pediatric mood literature - is discussed in a paper by Krieger et al. ${ }^{3}$ The authors focus on two polemic issues, namely the misdiagnosis of chronic irritability as pediatric bipolar disorder and the new category of disruptive mood dysregulation disorder included in DSM-5.

Recent advances in the diagnosis and treatment of attention-deficit/hyperactivity disorder (ADHD) are presented by Dias et al. ${ }^{4}$ Neurobiological findings in ADHD research converge to identify delays in maturational processes as a core feature of the disorder. The well demonstrated short-term efficacy of therapeutic strategies has to be expanded with studies focusing on interventions for preschool children and also with longer follow-up periods. Substance use disorders (SUD) impose an enormous burden on adolescents, who are especially vulnerable to enter a pathway of abuse and dependence. The article by Lopes et al. ${ }^{5}$ discusses issues related to the presentation and diagnosis of SUD in adolescence and the use of broad interventions, with the involvement of families and schools to prevent and treat SUD.

Autism spectrum disorders (ASD) are reviewed in the article by Brentani et al. ${ }^{6}$ The authors discuss the various presentations of ASD in the first years of life, emphasizing the need for prompt identification of cases in order to initiate intervention as soon as possible. An increasing number of evidence-based psychosocial and pharmacological strategies are currently available to decrease the burden of ASD on patients and their families.

The fact that most mental disorders have their origins early in life makes the work with children and adolescents relevant not only to child psychiatrists. Rather, we hope that this supplement will bring relevant and timely evidencebased information to any clinician and investigator willing to reduce the burden of mental disorders across the life span.

\section{Disclosure}

Christian Kieling receives research grants from Conselho Nacional de Desenvolvimento Científico e Tecnológico (CNPq), Coordenação de Aperfeiçoamento de Pessoal de Nível Superior (CAPES), and Fundação de Amparo à Pesquisa do Estado do Rio Grande do Sul (FAPERGS). He has also received royalties from Artmed and Manole, and research support from Deva and Novartis. Guilherme V. Polanczyk has served as a speaker and/or consultant to EliLilly, Novartis, Janssen-Cilag, and Shire Pharmaceuticals; has developed educational material to Janssen-Cilag; receives authorship royalties from Manole Editors; and has received unrestricted research support from Novartis.

\section{References}

1 Salum GA, DeSousa DA, do Rosário MC, Pine DS, Manfro GG. Pediatric anxiety disorders: from neuroscience to evidence-based clinical practice. Rev Bras Psiquiatr. 2013;35(Suppl 1):S3-21.

2 Rocha TB, Zeni CP, Caetano SC, Kieling C. Mood disorders in childhood and adolescence. Rev Bras Psiquiatr. 2013;35(Suppl 1):S22-31.

3 Krieger FV, Leibenluft E, Stringaris A, Polanczyk GV. Irritability in children and adolescents: past concepts, current debates, and future opportunities. Rev Bras Psiquiatr. 2013;35(Suppl 1):S32-9.

4 Dias TG, Kieling C, Graeff-Martins AS, Moriyama T, Rohde LA, Polanczyk GV. Developments and challenges in the diagnosis and treatment of ADHD. Rev Bras Psiquiatr. 2013;35(Suppl 1):S40-50.

5 Lopes GM, Nóbrega BA, Del Prette G, Scivoletto S. Use of psychoactive substances by adolescents: current panorama. Rev Bras Psiquiatr. 2013;35(Suppl 1):S51-61.

6 Brentani H, de Paula CS, Bordini D, Rolim D, Sato F, Portolese J, et al. Autism spectrum disorders: an overview on diagnosis and treatment. Rev Bras Psiquiatr. 2013;35(Suppl 1):S62-72. 